\title{
Exploring Orange Peel Treatment with Deep Eutectic Solvents and Diluted Organic Acids
}

\section{Van den Bruinhorst $\mathrm{A}^{1}$, Kouris $\mathrm{PD}^{2}$, Timmer $\mathrm{JMK}^{3}$, de Croon MHJM ${ }^{4}$ and Kroon MC $^{1,5^{*}}$}

${ }^{1}$ Separation Technology Group, Department of Chemical Engineering and Chemistry, Eindhoven University of Technology, Groene Loper 5, building 14 (Helix), 5612 AE, Eindhoven, The Netherlands

${ }^{2}$ Molecular Catalysis Group, Department of Chemical Engineering and Chemistry, Eindhoven University of Technology, Groene Loper 5, building 14 (Helix), 5612 AE, Eindhoven, The Netherlands

${ }^{3}$ Chemical Reactor Engineering Group, Department of Chemical Engineering and Chemistry, Eindhoven University of Technology, Groene Loper 5, building 14 (Helix), 5612 AE, Eindhoven, The Netherlands

${ }^{4} E T D \& C$ BV Bospoort 11-A, 6711 BT, Ede, The Netherlands

${ }^{5}$ Applied Thermodynamics and Separation Technology, Chemical Engineering Department, The Petroleum Institute, Bu Hasa Building, PO Box 2533, Abu Dhabi, United Arab Emirates

\begin{abstract}
The disintegration of orange peel waste in deep eutectic solvents and diluted organic acids is presented in this work. The albedo and flavedo layers of the peel were studied separately, showing faster disintegration of the latter. Addition of water to the deep eutectic solvents lowered the amount of remaining solids and improved the disintegration times. These improvements are subscribed to a decrease in viscosity upon deep eutectic solvent dilution. Each of the individual deep eutectic solvent components were diluted and subjected to the same disintegration tests. The corresponding diluted organic acids showed similar orange peel disintegration performance as the tested deep eutectic solvents, whereas dilutions of the other counterparts did not show any activity. Hence, the active deep eutectic solvent components during orange peel treatment are considered to be their organic acids. Flavonoids and essential oils were released during the treatment, offering new opportunities for the development of orange peel waste valorisation routes.
\end{abstract}

Keywords: Deep eutectic solvents; Orange peel; Food waste; Disintegration

\section{Introduction}

Waste is a term that is quickly associated with landfills, pollution and domestic garbage. Nowadays, however, waste streams are increasingly regarded as renewable sources for materials and chemicals. Crop residues in particular are globally abundant and potentially rich in added-value functionalised components e.g., fibres, oils, proteins, waxes, dyes, and flavonoids [1-3]. Obtaining residues with constant quality and composition is challenging though, for instance due to decentralised harvesting and seasonal influences.

Food processing facilities could offer a well-defined waste stream, since they have to deliver products that constantly meet quality standards. Orange peels (OPs) are an excellent example of processing residues that contain many potential products [4]. In Table 1 the composition of OPs is shown, highlighting the currently commercially exploited compounds. Roughly 71 Mton of oranges were produced worldwide in 2013 [5]. Approximately $40 \%$ of all harvested oranges are treated by the juicing and canning industries, of which $40-50 \mathrm{wt} . \%$ ends up as processing peel waste [6].

Despite its great potential [7], OP waste is often still used as lowvalue animal feed additive [8], digested, incinerated or even dumped [9]. Prevailing OP valorisation processes focus on the subsequent recovery of essential oils (mainly d-limonene) and/or pectin. Essential oils are traditionally recovered by cold pressing, steam/hydrodistillation or solvent extraction. Cold pressing and distillation require high mechanical and thermal energy inputs, respectively. Additionally, the elevated temperatures applied (distillation) and the presence of air at elevated pressures (cold pressing) can alter the chemical composition of the oils $[10,11]$. Depending on the quality of the remaining solids after essential oil isolation, pectin recovery is performed in series or as a separate process. For pectin production, OP is commonly subjected to a mineral acid hydrolysis step followed by ethanol precipitation [12], causing unwanted salt formation upon waste water neutralization.
Many new techniques have evolved for OP treatment, aiming at decreased energy usage, orange oil/pectin quality improvements and process intensification [4]. Among them are ultrasound [13-15], microwave [14,16], supercritical fluid [17] and ionic liquid [11] (IL) extraction. Ultrasound and microwave processes modify biomass cells, accelerate mass transfer rates and the latter are able to heat samples rapidly and accurately $[3,16]$. These physical treatments are therefore often used to complement affinity extractions with solvents like ILs [18]. ILs can be roughly defined as (organic) salts that melt below $100^{\circ} \mathrm{C}$. By designing combinations of cations and anions, new taskspecific solvents can be synthesized. The ILs that proved to dissolve lignocellulosic biomass $[19,20]$ were also screened for OP processing [11].

Following this strategy, the deep eutectic solvents (DESs) that showed biopolymer dissolution in our previous study [21] were selected for OP treatment in this work, see Table 2. DESs are mixtures of two or more components that exhibit (extreme) eutectic behaviour due to self-association, resulting in a liquid at temperatures below the melting temperatures of its individual components [22]. This allows the utilization of their functional groups at mild temperatures without an additional solvent. In 2004, DESs were presented as an alternative to ILs [23], mainly because they display similar physicochemical properties but are prepared more easily. By mixing the components under mild heating, a clear DES can be formed without further purification.

*Corresponding author: Maaike C Kroon, Applied Thermodynamics and Separation Technology, Chemical Engineering Department, The Petroleum Institute, Bu Hasa Building, PO Box 2533, Abu Dhabi, United Arab Emirates, Tel: +97126075317; Fax: +97126075200; E-mail: mkroon@pi.ac.ae

Received October 12, 2016; Accepted October 19, 2016; Published October 24 2016

Citation: Van den Bruinhorst A, Kouris PD, Timmer JMK, de Croon MHJM Kroon MC (2016) Exploring Orange Peel Treatment with Deep Eutectic Solvents and Diluted Organic Acids. Nat Prod Chem Res 4: 242. doi: 10.4172/23296836.1000242

Copyright: ( $) 2016$ Van den Bruinhorst A, et al. This is an open-access article distributed under the terms of the Creative Commons Attribution License, which permits unrestricted use, distribution, and reproduction in any medium, provided the original author and source are credited. 
It is likely that the studied DESs show different interactions to each of the components listed in Table 1, hence the structure of OP is of relevance. OPs mainly consist of two layers, the albedo (inner) and flavedo (outer) layer, which account for about 25 and $10 \mathrm{wt} . \%$ of the whole fruit, respectively. The albedo is the white spongy cellulose, starch and pectin-rich part, containing most of the flavonoids, amino acids and vitamins [4]. The typical orange colour and odour are provided by the flavedo, embedding the essential oil glands and lignin [4]. Considering the low starch and cellulose and the high lignin solubilities found for the DESs in the aforementioned screening [21], it was expected that flavedo disintegrates more easily than albedo.

\section{Materials and Methods}

Glycolic acid ( $\geq 99 \%)$, choline chloride $(\geq 98 \%)$ and L-proline (pharmaceutical grade) were purchased at Sigma-Aldrich. DLMalic acid $(\geq 99 \%)$ and $\mathrm{D}(+)$-glucose $\left(\geq 90 \%, 8-10 \% \mathrm{H}_{2} \mathrm{O}\right)$ were acquired from Merck Milipore and crystalline Purac L-lactic acid (pharmaceutical grade) was kindly provided by Corbion Purac Biochem BV. The chemicals were used without further purification. Deionized water $\left(18.2 \mathrm{M} \Omega \cdot \mathrm{cm}^{-1}\right)$ was obtained from a Millipore Milli-Q' biocell equipped with a Q-grade column and is hereafter called MilliQ water. Navel oranges were purchased at the local supermarket (Albert Heijn).

\section{DES preparation}

An overview of the prepared DESs and their molar ratios is given in Table 3. The DES components were weighed on a Sartorius Extend analytical balance and added to a screw capped glass flask with magnetic stirring bar. The flask was heated in a thermostatic oil bath (IKA ETS-D5 controller, accuracy $\pm 0.2 \mathrm{~K}$, precision $\pm 0.1 \mathrm{~K}$ ) while being stirred at $150 \mathrm{rpm}$ until a clear liquid was obtained. Lactic and glycolic acid based DESs were prepared at $60^{\circ} \mathrm{C}$ and malic acid based DESs were prepared at $80^{\circ} \mathrm{C}$. The water content of the prepared DESs was determined with a 795 KFT Titrino Metrohm Karl Fischer. If the water content exceeded $1 \mathrm{wt} . \%$, the DES was dried under vacuum in a desiccator with silica gel until the water content was below $1 \mathrm{wt} . \%$. The diluted DESs $-5,10$ and 20 wt.\% of water- were prepared by pipetting water to untreated DESs, correcting for the initial water content.

\section{Orange peel treatment}

OP was carefully cut with a scalpel into pieces of approximately 2 $\times 2 \times 2-5 \mathrm{~mm}$. Extra attention was paid while cutting the flavedo in order to maintain the oil glands and prevent the release of essential oil before extraction. The dissolution experiments were performed in 100 $\mathrm{mL}$ screw capped flasks or round-bottomed flasks. The total weight of the solution was always $30 \mathrm{~g}$, the peel (fraction) was added to the DES according to the biomass loading. The mixtures of DES and OP were placed in a thermostatic oil bath at either 50 or $80^{\circ} \mathrm{C}$ (IKA ETS-D5 controller) and stirred with a magnetic stirring bar at $300 \mathrm{rpm}$. Every 30

\begin{tabular}{|c|c|}
\hline Compounds & wt.\% (dry weight basis) \\
\hline Soluble sugars [12,28-31] & $10-41$ \\
\hline Cellulose [12,28-33] & $9-37$ \\
\hline Hemicellulose [28-33] & $6-14$ \\
\hline Lignin [12,28-30,32,33] & $1-9$ \\
\hline Pectin [28-31] & $14-43$ \\
\hline Oils and fat (incl. d-limonene) [28-31] & $2-6$ \\
\hline Flavonoid [28,31] & $4-6$ \\
\hline Protein [12,28-31,33] & $6-9$ \\
\hline Ash [12,28-32] & $2-4$ \\
\hline
\end{tabular}

Table 1: Composition of orange peels, commercially exploited compounds are highlighted. minutes the flasks were exposed to an intensive light source to monitor the remaining particle sizes and a photo was taken.

\section{pH measurement}

$\mathrm{pH}$ measurements were performed with a WTW series Inolab 730 $\mathrm{pH}-$ meter equipped with a glass probe SenTix81 (pH 0-14/T 0-100 ${ }^{\circ} \mathrm{C} / 3$ $\mathrm{mol} \mathrm{dm}{ }^{-3} \mathrm{KCl}$ ). Before each measurement, the device was calibrated with buffer solutions of $\mathrm{pH}=4$ (WTW 4.00 technical buffer) and $\mathrm{pH}=1$ (Merck Titrisol $\left.1.00 \pm 0.02\left(20^{\circ} \mathrm{C}\right)\right)$ and the electrode was rinsed with MilliQ water.

\section{Results and Discussion}

Intact OP, separate flavedo, and separate albedo particles (Figure 1) were treated with DESs (water content $<1$ wt.\%). Initially, suspensions with a total weight of $30 \mathrm{~g}$ and $20 \mathrm{wt} . \%$ peel loading were prepared for the three peel fractions and all selected DESs. No dissolution was observed for any of the tested DESs at $50^{\circ} \mathrm{C}$. The temperature was increased to $80^{\circ} \mathrm{C}$ for GlyA:ChCl 3:1 and MaliA:ChCl 1:1. MaliA:ChCl 1:1 only showed partial disintegration for flavedo, no significant effect was observed for OP and albedo. For GlyA: $\mathrm{ChCl} \mathrm{3:1} \mathrm{however,} \mathrm{no} \mathrm{intact}$ OP or flavedo particles were observed after treatment, while the albedo disintegrated to a much lesser extent (Table 3). This confirms that DESs disintegrate flavedo easier than albedo.

A possible explanation for the complete and relatively fast disintegration of OP compared to albedo, is that the released components from the flavedo promote carbohydrate hydrolysis. The $\mathrm{pH}$ of OP can reach values as low as 3.64 [9]. In order to explore the capacity of GlyA:ChCl 3:1, the peel loading was increased to $30 \mathrm{wt} . \%$. After $24 \mathrm{~h}$, the peel was only partially disintegrated. The treatment reduced the OP particle size significantly, the remaining fibres were swollen and had a pale colour (Figure 2). It is therefore likely that the flavedo has been disintegrated, but part of the albedo endured.

Following Table 3, GlyA: $\mathrm{ChCl}$ 3:1 shows resembling disintegration times compared to the ILs that were tested by Bica et al. [11]. For both the DES GlyA:ChCl 3:1 and the IL [C2mim] OAc an increase in peel loading results in a tremendous increment of the treatment time. Although an explanation of this behaviour is not given for the ILs, it was observed that the viscosity of the OP solution increased substantially during the dissolution experiments for the DESs. A likely cause of this viscosity increase is the release of pectin, a gelling agent used for cosmetic and food grade purposes. After the disintegration of $20 \mathrm{wt} . \%$ of OP, the resulting mixture behaved like an immobilized gel at

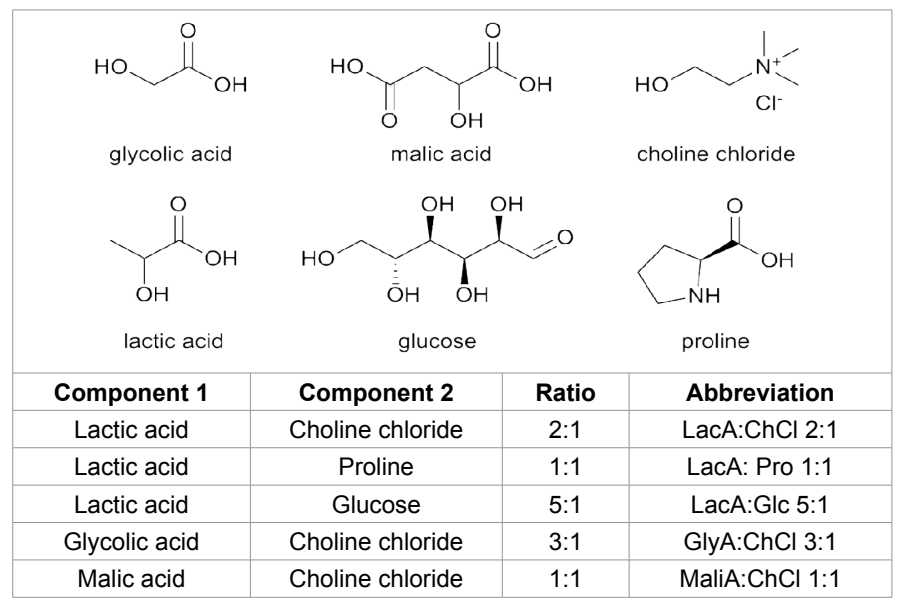

Table 2: An overview of the deep eutectic solvents used for orange peel treatment. 


\begin{tabular}{|c|c|c|c|c|}
\hline Solvent & Peel loading & Peel type & Disintegration & Time (h) \\
\hline GlyA:ChCl 3:1 & $10 \mathrm{wt} \%$ & $\mathrm{OP}$ & complete & 4 \\
\hline GlyA:ChCl 3:1 & $20 w t \%$ & $\mathrm{OP}$ & complete & 5.5 \\
\hline GlyA:ChCl 3:1 & $20 \mathrm{wt} \%$ & flavedo & complete & 5 \\
\hline GlyA:ChCl 3:1 & $20 \mathrm{wt} \%$ & albedo & partial & 24 \\
\hline GlyA:ChCl 3:1 & $30 \mathrm{wt} \%$ & OP & partial & 24 \\
\hline$\left[\mathrm{C}_{2} \mathrm{mim}\right] \mathrm{OAC}^{\mathrm{a}}$ & 20 wt.\% & OP & complete & 3 \\
\hline$\left[\mathrm{C}_{2}\right.$ mim $] \mathrm{OAC}^{a}$ & 30 wt.\% & OP & complete & 24 \\
\hline$\left[\mathrm{C}_{2}\right.$ mim $] \mathrm{OAC}^{a}$ & 50 wt. \% & $\mathrm{OP}$ & none & 24 \\
\hline$\left[\mathrm{C}_{4} \mathrm{mim}\right] \mathrm{Cl}^{\mathrm{a}}$ & 20 wt. \% & OP & partial & 24 \\
\hline$[\mathrm{Amim}] \mathrm{Cl}^{\mathrm{a}}$ & 20 wt. $\%$ & OP & partial & 24 \\
\hline
\end{tabular}

a Data reprinted from Bica et al. [11]

Table 3: Results of the disintegration experiments at $80^{\circ} \mathrm{C}$, with orange peel (OP), flavedo and albedo at different peel loadings. The disintegration was considered complete when no intact OP particles could be observed visually.
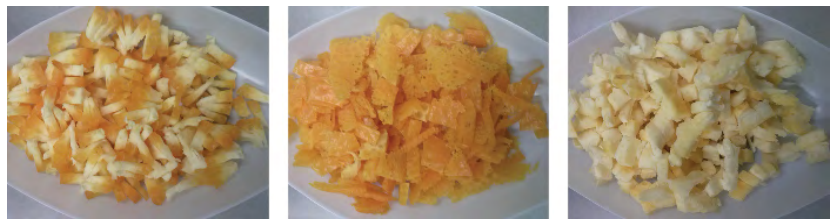

Figure 1: Different types of peel used for DES treatment: orange peel (left) flavedo (middle) and albedo (right). All carefully cut into pieces of approximately $2 \times 2 \times 2-5 \mathrm{~mm}$. Different types of peel used for DES treatment: orange peel (left), flavedo (middle) and albedo (right). All carefully cut into pieces of approximately $2 \times 2 \times 2-5 \mathrm{~mm}$.
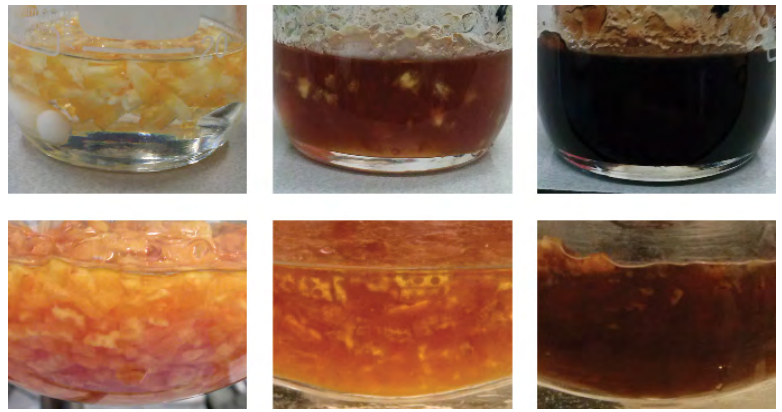

Figure 2: Orange peel treatment with GlyA: $\mathrm{ChCl} 3: 1$ at $80^{\circ} \mathrm{C}$, at peel loadings of 20 wt.\% (top row) and 30 wt.\% (bottom row). Left to right: $t=0, t=1$ and $\mathrm{t}=5.5 / 24 \mathrm{~h}$ (top/bottom).

room temperature. Lowering the OP loading to $10 \mathrm{wt} . \%$ had a positive effect on the disintegration time and the viscosity was decreased significantly. Nonetheless, the DESs exhibited extreme viscosities at ambient temperatures after OP treatment.

In literature, it is suggested that the physicochemical properties of DESs, e.g., viscosity, can be tuned upon water addition [24-26]. Up to water contents of $25 \mathrm{wt} . \%$, the intermolecular hydrogen bonding network between the DESs' components is still predominant [24,25]. Water solvation of the individual DES components occurs between water contents of 25 and $50 \mathrm{wt} . \%$. The viscosity of DESs typically decreases by one order of magnitude if $25 \mathrm{wt} . \%$ of water is added. To overcome the viscosity limitations mentioned previously, it was decided to perform the dissolution experiments with DESs containing 5, 10 and $20 \mathrm{wt} . \%$ of water. Dried GlyA:ChCl 3:1 (0.85 wt.\% water) has a viscosity of $275 \mathrm{mPa} \cdot \mathrm{s}$ at $25^{\circ} \mathrm{C}$, after dilution (20.1 wt.\% water) the viscosity dropped to $15.4 \mathrm{mPa} \cdot \mathrm{s}$ at $25^{\circ} \mathrm{C}$ (method used: Supporting Information 2).

Besides GlyA:ChCl 3:1, the LacA:Glc 5:1 DES was selected, since its components are present in or derivable from the OP and it proved to extract plant metabolites [27]. LacA:Glc 5:1 belongs to a sub-category of DESs - the so-called NADESs - because it is composed of natural components and does not form a liquid at room temperature without water addition [24,27]. The addition of water to the DESs prior to OP treatment accelerates the disintegration process (Table 4). A higher water content also results in a higher $\mathrm{pH}$, since the system becomes more diluted. Figure 3 shows that the disintegration time decreases with increasing $\mathrm{pH}$ for both $\mathrm{DES}$ systems. This is ascribed to a vast decrease in viscosity and the fact that the systems remain very acidic $(\mathrm{pH}<1)$. At initial DES water contents above $25 \mathrm{wt} . \%$, the disintegration time is still improved. Hence, the preservation of the DES's hydrogen bonding network is not determinant for disintegration of OP.

In order to examine if one of the individual components is solely responsible for OP disintegration, water dilutions of glycolic acid, lactic acid, glucose and choline chloride were prepared. For glucose and choline chloride no disintegration was detected after a treatment of $24 \mathrm{~h}$ at $80^{\circ} \mathrm{C}$. All lactic acid and glycolic acid dilutions disintegrated the $\mathrm{OP}$, resulting in a coloured suspension. For the more dilute systems, only tested for diluted acids, the dissolution time increases with increasing $\mathrm{pH}$. It is assumed that the viscosity is relatively unaffected by further dilution at the presented water contents (all $>70 \mathrm{wt} . \%$ ). Probably, the acidity of the solvent is mainly responsible for the disintegration of the albedo part, in that case, an increased $\mathrm{pH}$ lowers the activity of the solvent.

A set of samples was filtered after treatment in order to verify the visual observations of complete disintegration and compare the performance of DES, diluted DES and diluted acid. The results are listed in Table 5 and show that despite the observation of complete disintegration, a significant amount of the added solids is still present after treatment as small fibres. This amount of remaining solids decreases considerably upon initial water addition to the DES. The DES and diluted glycolic acid show similar activities. The initial approach was to use DESs for OP treatment, however diluted organic acids show the same performance at lower concentrations. The lowest amounts of remaining solids are found for the diluted DES batches. This might be partially attributed to the added water that improves the mobility of the salt's ions, allowing choline chloride to improve the OP disintegration. OP treatment with choline chloride solutions did not lead to disintegration, but lowering the $\mathrm{pH}$ by increasing the

\begin{tabular}{|c|c|c|c|c|}
\hline Solvent & $\mathbf{5}$ wt. $\%$ & $\mathbf{1 0}$ wt. $\%$ & $\mathbf{2 0}$ wt.\% & $\mathbf{5 0}$ wt. $\%$ \\
\hline GlyA:ChCl 3:1 & n.d. & $2.5 \mathrm{~h}$ & $1.5 \mathrm{~h}$ & $1 \mathrm{~h}$ \\
\hline LacA:Glc 5:1 & $3.5 \mathrm{~h}$ & $2.5 \mathrm{~h}$ & $2 \mathrm{~h}$ & $1 \mathrm{~h}$ \\
\hline
\end{tabular}

Table 4: The influence of the initial water content of deep eutectic solvents (wt.\%) on the orange peel treatment time at which no intact OP particles were observed (h). All experiments were performed at $80^{\circ} \mathrm{C}$, with a peel loading of $10 \mathrm{wt} . \%$.

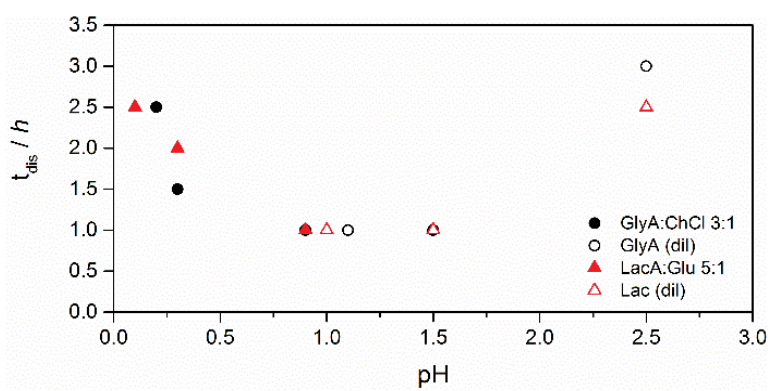

Figure 3: Disintegration time as function of $\mathrm{pH}$ of the diluted DES and their diluted corresponding acids. Water contents of the diluted DES are 10, 20 and 50 wt.\% from low to high $\mathrm{pH}$ (Supporting Information 1). 


\begin{tabular}{|c|c|}
\hline Solvent & Solids (wt.\%) \\
\hline Diluted glycolic acid $(\mathrm{pH}=1.45) \mathrm{A}$ & 38.1 \\
\hline Diluted glycolic acid $(\mathrm{pH}=1.45) \mathrm{B}$ & 39.7 \\
\hline Diluted glycolic acid $(\mathrm{pH}=1) \mathrm{A}$ & 36.7 \\
\hline Diluted glycolic acid $(\mathrm{pH}=1) \mathrm{B}$ & 35.4 \\
\hline Diluted GlyA:ChCl 3:1 (20 wt.\% water) A & 23.9 \\
\hline Diluted GlyA:ChCl 3:1 (20 wt.\% water) B & 24.2 \\
\hline GlyA:ChCl 3:1 A & 34.2 \\
\hline GlyA:ChCl 3:1 B & 35.3 \\
\hline
\end{tabular}

Table 5: Remaining solids after OP treatment (Supporting Information 2), expressed in \% dry weight after treatment / dry weight added OP (wt.\%) for different solvents. Tests were performed in duplo, batch $\mathrm{A}$ and $\mathrm{B}$. All experiments were performed at $80^{\circ} \mathrm{C}$ for $2 \mathrm{~h}$, with a peel loading of $10 \mathrm{wt} . \%$ (wet basis).

acid content improved both the disintegration time and decreased the remaining solids. The acid thus seems to act as the active component for OP disintegration. The viscosity is likely to be a limiting factor, hence the combination of a relatively low viscosity and high glycolic acid concentration ( $49 \mathrm{wt} \%$ for the diluted DES) lead to a more complete disintegration.

The limiting step of OP disintegration process is probably the hydrolysis of carbohydrate fibres. This is in line with the previously reported results: lignin [21] and flavedo dissolve relatively readily, while cellulose [21] and albedo require harsher conditions (Table 3). Although these trends can be recognized, a more detailed study to the OP disintegration process is necessary. It might be possible to regulate the product release during $\mathrm{OP}$ treatment by tuning the process conditions. After processing the $\mathrm{OP}$ at $80^{\circ} \mathrm{C}$, both the flavonoid hesperidin and the terpene d-limonene were tentatively detected in the liquid (Supporting Information 2 and 3). These products could be isolated in further separation processes, like liquid-liquid extraction or distillation. Alternatively, the liquefied OP could serve as a cosmetic product, since the DESs can be prepared from generally regarded as safe (GRAS) materials [28-33].

\section{Conclusions}

DESs were used to disintegrate $\mathrm{OP}$ particles at $80^{\circ} \mathrm{C}$. As was expected, the flavedo part of the peel was disintegrated easier than the albedo. An extended study to the influence of process conditions on this behaviour, might open pathways for selective flavedo removal. The viscosity seems to be the most limiting factor in the disintegration process. Diluting the DESs with water prior to the treatment can overcome this limitation. The acid of the DESs appears to be the active component for the disintegration of the albedo part of OPs. The dilutions of the DESs's corresponding acids were as effective during OP treatment as DESs, hence the incorporation of choline chloride and glucose is debatable. However, a detailed composition analysis of the resulting liquids and remaining solids should be performed to explicate the role of each DES component during the OP disintegration. Additionally, other potential products than the identified hesperidin and d-limonene might be unveiled, allowing the valorisation of OP through treatment with DESs.

\section{Supporting Information}

More information on the $\mathrm{pH}$ after disintegration, used methodology, and hesperidin and limonene detection can be found in the supporting information.

\section{Acknowledgements}

This work was part of the TKI NCl Kiem program (contract 731.013.111), which is financed by the Netherlands Organisation for Scientific Research (NWO). We gratefully acknowledge additional financial support by ETD\&C BV and Corbion Purac Biochem BV for the provision of crystalline Purac ${ }^{\circledR}$ L-lactic acid (pharmaceutical grade). Special thanks to Jaap van Spronsen for his help and fruitful discussions.

\section{Conflict of Interests Disclosure}

The authors declare no competing financial interest.

\section{References}

1. Tuck CO, Pérez E, Horváth IT, Horváth IT, Sheldon RA, et al. (2012) Valorization of biomass: deriving more value from waste. Science 337: 695-699.

2. Santana-Méridas O, González-Coloma A, Sánchez-Vioque R (2012) Agricultural residues as a source of bioactive natural products. Phytochem Rev 11: 447-466.

3. Galanakis CM (2012) Recovery of high added-value components from food wastes: conventional, emerging technologies and commercialized applications. Trends Food Sci Tech 26: 68-87.

4. Mamma D, Christakopoulos $P$ (2014) Biotransformation of citrus by-products into value added products. Waste Biomass Valor 5: 529-549.

5. Food and Agriculture Organization of the United Nations - Statistics Division Orange production 2013. Accessed 6 Feb 2015.

6. Pfaltzgraff LA, De Bruyn M, Cooper EC, Vitaly B, Clark JH (2013) Food waste biomass: a resource for high-value chemicals. Green Chem 15: 307-314.

7. Ledesma-Escobar CA, de Castro MDL (2014) Towards a comprehensive exploitation of citrus. Trends Food Sci Tech 39: 63-75.

8. Tripodo MM, Lanuzza F, Micali G, Rosa C, Fortunata N (2004) Citrus waste recovery: a new environmentally friendly procedure to obtain animal feed. Bioresour Technol 91: 111-115.

9. Angel Siles López J, Li Q, Thompson IP (2010) Biorefinery of waste orange peel. Crit Rev Biotechnol 30: 63-69.

10. Ferhat MA, Meklati BY, Chemat F (2007) Comparison of different isolation methods of essential oil from Citrus fruits: cold pressing, hydrodistillation and microwave "dry" distillation. Flavour Frag J 22: 494-504.

11. Bica K, Gaertner P, Rogers RD (2011) Ionic liquids and fragrances-direct isolation of orange essential oil. Green Chem 13: 1997-1999.

12. Grohmann K, Cameron R, Buslig B (1995) Fractionation and pretreatment of orange peel by dilute acid hydrolysis. Bioresour Technol 54: 129-141.

13. Pingret D, Fabiano-Tixier A-S, Chemat F (2014) An Improved Ultrasound Clevenger for Extraction of Essential Oils. Food Anal Methods 7: 9-12.

14. Boukroufa M, Boutekedjiret $C$, Petigny $L$ (2015) Bio-refinery of orange peels waste: A new concept based on integrated green and solvent free extraction processes using ultrasound and microwave techniques to obtain essential oil, polyphenols and pectin. Ultrason Sonochem 24: 72-79.

15. Khan MK, Abert-Vian M, Fabiano-Tixier AS, Olivier D, Farid C (2010) Ultrasound-assisted extraction of polyphenols (flavanone glycosides) from orange (Citrus sinensis L.) peel. Food Chem 119: 851-858.

16. Kratchanova M, Pavlova E, Panchev I (2004) The effect of microwave heating of fresh orange peels on the fruit tissue and quality of extracted pectin. Carbohydr Polym 56: 181-185.

17. Mira B, Blasco M, Berna A, Subirats S (1999) Supercritical CO2 extraction of essential oil from orange peel. Effect of operation conditions on the extract composition. J Supercrit Fluids 14: 95-104.

18. Tang B, Bi W, Tian M, Row KH (2012) Application of ionic liquid for extraction and separation of bioactive compounds from plants. J Chromatogr B Analyt Technol Biomed Life Sci 904: 1-21.

19. Sun N, Rodríguez H, Rahman M, Rogers RD (2011) Where are ionic liquid strategies most suited in the pursuit of chemicals and energy from lignocellulosic biomass? Chemm Commun 47: 1405-1421.

20. Domínguez de María P (2013) Recent trends in (ligno) cellulose dissolution using neoteric solvents: Switchable, distillable and bio-based ionic liquids. J Chem Technol Biotechnol 89: 11-18.

21. Francisco M, van den Bruinhorst A, Kroon MC (2012) New natural and renewable low transition temperature mixtures (LTTMs): screening as solvents for lignocellulosic biomass processing. Green Chem 14: 2153-2157. 
Citation: Van den Bruinhorst A, Kouris PD, Timmer JMK, de Croon MHJM, Kroon MC (2016) Exploring Orange Peel Treatment with Deep Eutectic Solvents and Diluted Organic Acids. Nat Prod Chem Res 4: 242. doi: 10.4172/2329-6836.1000242

22. Zhang Q, Vigier KDO, Royer S, Jérôme F (2012) Deep eutectic solvents: syntheses, properties and applications. Chem Soc Rev 41: 7108-7146.

23. Abbott AP, Boothby D, Capper G (2004) Deep eutectic solvents formed between choline chloride and carboxylic acids: versatile alternatives to ionic liquids. J Am Chem Soc 126: 9142-9147.

24. Dai Y, Witkamp GJ, Verpoorte R, Choi YH (2015) Tailoring properties of natural deep eutectic solvents with water to facilitate their applications. Food Chem 187: 14-19.

25. Shah D, Mjalli FS (2014) Effect of water on the thermo-physical properties of Reline: An experimental and molecular simulation based approach. Phys Chem Chem Phys 16: 23900-23907.

26. Gutiérrez MC, Ferrer ML, Mateo CR, del Monte F (2009) Freeze-drying of aqueous solutions of deep eutectic solvents: a suitable approach to deep eutectic suspensions of self-assembled structures. Langmuir 25: 5509-5515.

27. Dai Y, Witkamp GJ, Verpoorte R, Choi YH (2013) Natural deep eutectic solvents as a new extraction media for phenolic metabolites in Carthamus tinctorius $\mathrm{L}$. Anal Chem 85: 6272-6278
28. Marín FR, Soler-Rivas C, Benavente-García O, Julian C, Pérez-Alvarez JA (2007) By-products from different citrus processes as a source of customized functional fibres. Food Chem 100: 736-741.

29. Rivas B, Torrado A, Torre P, Attilio C, Domínguez JM (2008) Submerged citric acid fermentation on orange peel autohydrolysate. J Agric Food Chem 56 2380-2387.

30. Mamma D, Kourtoglou E, Christakopoulos P (2008) Fungal multienzyme production on industrial by-products of the citrus-processing industry. Bioresour Technol 99: 2373-2383.

31. Bicu I, Mustata F (2011) Cellulose extraction from orange peel using sulfite digestion reagents. Bioresour Technol 102: 10013-10019.

32. Ververis C, Georghiou K, Danielidis D, Hatzinikolaoua DG, Santas $P$, et al. (2007) Cellulose, hemicelluloses, lignin and ash content of some organic materials and their suitability for use as paper pulp supplements. Bioresour Technol 98: 296-301.

33. Orozco RS, Hernández PB, Morales GR, Fernando UN, Villafuerte JO, et al. (2014) Characterization of lignocellulosic fruit waste as an alternative feedstock for bioethanol production. BioResources 9: 1873-1885. 